\title{
RESEÑA
}

\section{El Japón extraviado, vulnerable y en soledad}

DOI: $10.32870 /$ mycp.v9i27.703

Carlos Uscanga ${ }^{1}$

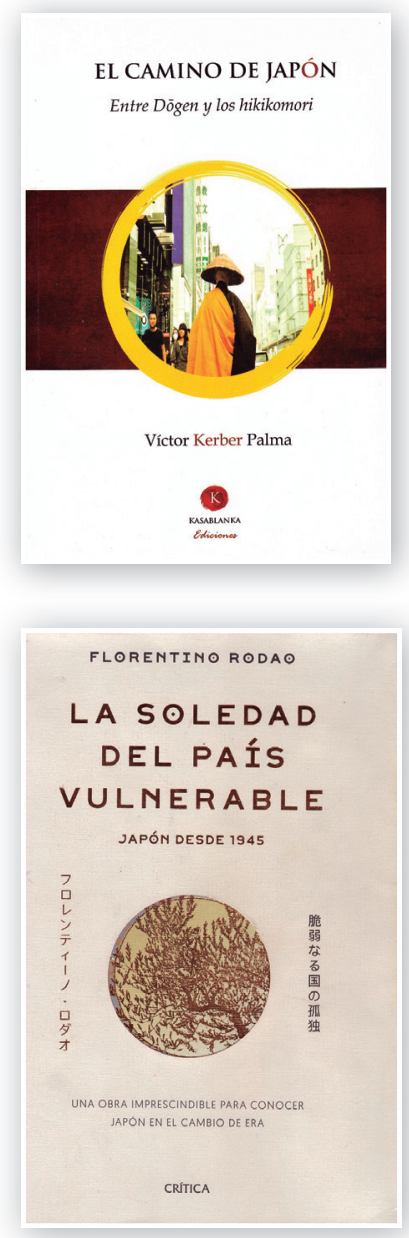

Kerber Palma, Víctor. (2019). El camino de Japón: Entre Dōgen y los Hikikomori, Ciudad de México, México: Kasablanka Ediciones/Fundación Kasuga.

Rodao, Florentino. (2019). La soledad del país vulnerable, Barcelona, España: Editorial Crítica.

En 2019, se publicaron dos libros en latitudes distintas dentro del mundo hispano que no solo tienen como común denominador el abordar (con diferentes ángulos) al Japón del siglo XXI, sino que también sus autores tuvieron una larga experiencia de vida y una muy productiva formación académica en ese país asiático. En muchos sentidos, Japón es un gran calidoscopio, las caprichosas imágenes que refleja deben ser interpretadas $-\mathrm{y}$ después reinterpretadas de nuevo- - para no caer en el simplismo de ser un espectador pasivo apreciando a ese país en un

1. Universidad Nacional Autónoma de México (UNAM), Facultad de Ciencias Políticas y Sociales, Centro de Relaciones Internacionales. Miembro del Sistema Nacional de Investigadores de CONACYT Nivel II. Reconocimiento del Ministerio de Asuntos Exteriores de Japón (2019) por sus aportaciones en la investigación y docencia en estudios japoneses en México. Circuito Mario de la Cueva s/n, Coyoacán, Cd. Universitaria, CDMX. México. C.P. 04510. ORCID: https://orcid.org/0000-0002-2010-227X Correo electrónico: auscanga@politicas.unam.mx 
escaparate de ultramodernidad alimentado por los estereotipos clásicos de la disciplina, armonía y orden de la sociedad japonesa.

Llegar al Japón profundo es una tarea compleja pero alcanzable en la medida de que se tengan las herramientas necesarias. Estas dos obras representan un esfuerzo para ofrecer al lector los instrumentos y las claves esenciales para analizar los profundos cambios experimentados por Japón de la posguerra. Para lograr ese objetivo, los autores parten de una estrategia basada en la recuperación de procesos relevantes en su historia contemporánea, identificando hechos que han marcado las transformaciones económicas, políticas y sociales pero dando voz a personajes que contribuyeron a forjar al Japón moderno, pero también destacando la acción de los actores económicos y sociales dentro de esa vertiginosa transmutación.

En lo particular, Florentino Rodao realiza una detallada, profunda y bien documentada revisión de los principales procesos que han marcado la historia de Japón durante los siglos xx y xxi. Con el estilo narrativo claro y preciso, el autor invita al lector a "desentrañar" a la nación japonesa a través de su sentimiento de soledad (inmersa en su insularidad aparente pero imposible) que al final de la Segunda Guerra Mundial — ante su calidad de país derrotado- tuvo que reajustar su percepción del mundo y modificar sus formas de inserción en el mismo dentro del bipolarismo y posteriormente en el unipolarismo de la pos-Guerra Fría.

Japón tiene varias vulnerabilidades desde las propias por su ubicación geográfica al ser víctima constante de tifones y otros desastres naturales, su alta sismicidad, el ser víctima de tsunamis letales como los que se pudieron observar en el terremoto del 11 de marzo de 2011, hasta sus debilidades como sociedad generadas por el decrecimiento de la tasa de fertilidad, que amenaza la mayor contracción poblacional - por causas naturales- que pueda sufrir una de las principales naciones industrializadas del mundo para lo que resta del presente siglo.

Víctor Kerber convoca a Eihei Dōgen, Kitaro Nishida, Yukichi Fukuzawa y otros más para comprender la naturaleza propia de la modernidad japonesa para generar las bases de su reproducción social y la interacción con la naturaleza, marcando un sendero que la sociedad ha forjado y adaptado con valores, principios y sus percepciones de la vida.

La estructura del libro de Rodao está compuesta por tres grandes apartados: el histórico que formalmente parte de la derrota de Japón en la Guerra del Pacífico, hasta el triple desastre del terremoto de Tōhoku. Los enfoques 
temáticos profundizan en el desarrollo de tópicos referidos a la cultura —y sus emergentes expresiones contemporáneas-así como, con gran meticulosidad, presenta al lector los claroscuros de la sociedad y la política de poder en Japón.

Asimismo, el autor refiere como temas esenciales a sus últimos tres capítulos como referidos a la identidad, el tema de las minorías y las falacias (como también lo refiere Kerber) del nihonjinron; además aborda la problemática de la difuminada memoria histórica en Japón por sus políticas de expansionismo militar durante el periodo de entreguerras y su participación en la Segunda Guerra Mundial, lo cual ha generado debates dentro y fuera de ese país asiático. El libro termina con una reflexión profunda sobre el tema de la vida y la muerte en Japón, partiendo de una revisión desde la perspectiva histórico-religiosa, en la que el shintō (el camino de las deidades) ocupa un lugar destacado en su detallada explicación.

Para Kerber, Japón - como una nación extraviada- experimenta una serie de sucesos extraordinarios dentro de esa zona de transición en la que se encuentra hoy día. La sociedad reverdece y se observa un rescate de la sabiduría precapitalista, ante el agotamiento del frenesí de la modernización (interpretada linealmente por muchos como una simple occidentalización) impuesta desde la Era Meiji y profundizada en la posguerra. Hoy día las jóvenes generaciones de japoneses anhelan un cambio y no desean seguir el ejemplo de sus abuelos y de sus padres en su comportamiento social y en su percepción del trabajo.

En este sentido, el autor manufactura una ruta de análisis en cuatro tiempos donde problematiza a Japón ante el mundo y el mundo en Japón. Al mismo tiempo, marca las causas de por qué el Japón (heroico y galante, como lo refería el escritor guatemalteco Enrique Gómez Carrillo) perdió su camino y cómo recuperar al Japón hermoso de Yasunari Kawabata, que lamentablemente no pudo llegar a verlo ante - como lo que refiere Kerber- una sociedad enloquecida ante la posmodernidad. En ese contexto, ¿ serán el zen posmoderno y el nuevo shintō capaces de representar las luces que se perciben a lo lejos del sendero sinuoso por el que Japón ha andado como espectro errante para que lo pueda guiar a resarcir sus vulnerabilidades y encontrar el fin de su penosa travesía? La respuesta a esa pregunta, el autor la desarrolla en los dos últimos capítulos de la obra presentando una argumentación cuidadosamente manufacturada para explicar que Japón está ingresando a una transformación superestructural donde la filosofía de zen de Dōgen apertura una ruta más iluminada para Japón de la Era Reiwa. 
Es muy interesante cómo los dos libros dialogan entre sí, en donde los autores identifican los problemas que padece Japón en la actualidad y cómo ese país no fue asertivo para identificarlos ante una larga embriaguez de la ultramodernidad, que paradójicamente, lo hizo perder su ruta con el deseo sin límite de embonar en una hiperoccidentalización desde la posguerra. Para Rodao, Japón es un galápago temerario, mientras Kerber hace un llamado a la sociedad japonesa para recuperar la armonía (和) con la naturaleza y emprender hacia un renovado humanismo.

También los dos autores, partieron (como motivación para escribir sus respectivos libros) del anuncio del deseo por parte del emperador Akihito de abdicar, después de la elaboración de un proyecto de ley por parte del gobierno de Shinzō Abe y su aprobación de la Dieta, se aprobó que el 20 de abril de 2019 fuera la fecha para el término de la Era Heisei (平成) y el 1 de mayo del mismo año daría inicio la Era Reiwa (令和), que significa “hermosa armonía”, misma que marcaría el ascenso del emperador Naruhito. Ante ese hecho, Rodao y Kerber se apresuraron a escribir sus respectivas obras a fin de ofrecer a los lectores un marco de análisis comprehensivo sobre las vicisitudes padecidas por Japón en las últimas décadas, así como las tareas pendientes y expectativas que implicará su inminente arribo a la tercera década del presente siglo.

Por último, los dos autores visualizaban la organización de los Juegos Olímpicos y Paralímpicos en el verano de 2020 como la oportunidad para relanzar - apunta Rodao - o servir de una plataforma para mostrar la auténtica japoneidad - infiere Kerber - que fusione lo mejor de su pasado con las metas de su futuro para mostrarse como una sociedad creativa e innovadora. La expansión mundial de la pandemia de COVID-19 provocó al último minuto - ante las reticencias de la administración de Abe-aplazarlos para 2021. Asimismo, los efectos económicos derivados de la paralización productiva y financiera a nivel mundial para contener las cadenas de transmisión de contagio de esa variedad de coronavirus, indudablemente postergará la recuperación de las bases de su modelo de crecimiento que han sido erosionadas desde inicios de la década de los noventa.

Sin duda, Japón está en una profunda encrucijada económica y social. ¿Es en la equidistancia entre "Oriente" y "Occidente" que refiere Kerber, que podrá emprender un camino de rescate de su pasado premoderno para edificar una ruta más diáfana hacia los retos como sociedad en el mediano y largo plazos? O también será, como menciona Rodao, el desplegar de nuevo su capacidad de reinvención para que Japón pueda forjar, de manera auténti- 
camente temeraria, un futuro más asequible y también deseable. En suma, la fórmula Rodao-Kerber permite a los lectores comprender al Japón de ayer, sus desafíos de hoy y sus temas pendientes que se vislumbran ante la Era Reiwa. 